\title{
A reducing trend of fasciolosis in slaughtered animals based on abattoir data in South of Iran
}

\author{
Manoochehr Shabani Kordshooli ${ }^{1}$, Kavous Solhjoo ${ }^{1,2}$, Belal Armand ${ }^{2}$, Hamidreza Dowlatkhah ${ }^{3}$ and \\ Masoud Esmi Jahromi
}

1. Department of Parasitic Disease, Zoonoses Research Center, Jahrom University of Medical Sciences, Jahrom, Iran;

2. Department of Parasitology and Mycology, Jahrom University of Medical Sciences, Jahrom, Iran; 3. Department of Parasitic Disease, Research Center for Non-Communicable Diseases, Jahrom University of Medical Sciences, Jahrom, Iran ; 4. Jahrom City Veterinary Offices, Jahrom, Iran.

Corresponding author: Belal Armand, e-mail: armand_pl91@yahoo.com, Co-authors: MSK: shabani.bi@gmail.com,KS: solhjouk@yahoo.com, HD: h_dowlatkhah@yahoo.com, MEJ: masoudesmi60@gmail.com

Received: 22-09-2016, Accepted: 14-03-2017, Published online: 20-04-2017

doi: 10.14202/vetworld.2017.418-423 How to cite this article: Kordshooli MS, Solhjoo K, Armand B, Dowlatkhah H, Jahromi ME (2017) A reducing trend of fasciolosis in slaughtered animals based on abattoir data in South of Iran, Veterinary World, 10(4): 418-423.

\begin{abstract}
Aim: Fascioliasis is a zoonosis infection caused by the liver trematodes (Fasciola spp.) which have been considered to be an important disease in livestock. After several large outbreaks, fascioliasis remains one of the serious health concerns of Iran. This study was conducted to evaluate the prevalence and possible trends of fascioliasis in slaughtered animals in South of Iran based on abattoir data during a period of 5 years.

Materials and Methods: The daily records for cattle, sheep, and goats slaughtered in the abattoir were extracted from the archived documents of the recent 5 years (2011-2015) and used as the source of data. The collected data were statistically analyzed for finding any probable correlation between the various factors associated with fasciolosis.

Results: Our results showed that $3.44 \%$ of all slaughtered animals during 2011-2015 were infected with Fasciola spp. The mean prevalence of fasciolosis for cattle, sheep, and goat was $11.15 \%, 5.22 \%$, and $2.15 \%$, respectively. In addition, the highest infection rate was in winter $(4.02 \%)$, and the lowest were entered in summer $(2.86 \%)$.

Conclusion: Our findings showed a reducing trend during the 5 years. Improving the animal husbandry and increasing the awareness through fasciolosis may be a logical explanation for this trend. Since there have been suggested numerous factors associated with the epidemiology of fasciolosis, further studies seem essential for better clarifying the various aspects of fasciolosis in areas.
\end{abstract}

Keywords: fasciolosis, livestock, prevalence, south of Iran, trend.

\section{Introduction}

Fascioliasis is an infection caused by the liver fluke Fasciola spp. which is traditionally considered as an important disease in livestock. A wide range of mammals is known as definitive hosts for these parasites such as camel, sheep, goats, and cattle which are the most frequent animals in human environment $[1,2]$. These parasites cause biliary cirrhosis in livers and may cause economic losses like diminution of milk and meat production and many disorders such as diarrhea, loss of weight gain, abdominal pain, anemia, and cachexia in infected animals [3-5]. Although fascioliasis is a well-noted veterinary problem throughout the world, recent studies report it as an important public health problem as well [6-11]. Human fascioliasis is traced in 51 countries of the five continents $[10,12]$.

Copyright: Kurdshooli, et al. Open Access. This article is distributed under the terms of the Creative Commons Attribution 4.0 International License (http://creativecommons.org/licenses/ by/4.0/), which permits unrestricted use, distribution, and reproduction in any medium, provided you give appropriate credit to the original author(s) and the source, provide a link to the Creative Commons license, and indicate if changes were made. The Creative Commons Public Domain Dedication waiver (http:// creativecommons.org/publicdomain/zero/1.0/) applies to the data made available in this article, unless otherwise stated.
In addition, many human infections may be misdiagnosed or simply not diagnosed, and hence, the number of human cases is likely greater than that is indicated by published data.

Iran is worth mentioning in this regards because of great health problems caused by fascioliasis [6,13-15]. Infection in animals and human is reported throughout the country [16-18]. As a significant example, in 90 s, a large fascioliasis outbreak, including thousands of human cases, were reported in the north of Iran [19-23]. The second outbreak occurred 10 years later, and several thousand people were infected [24].

Data on the prevalence of fasciolosis and its veterinary and economic importance are scarce. In the absence of statistically and epidemiologic data, evaluating liver fluke prevalence in livestock based on abattoirs statistics might be useful. Information related to fascioliasis in different animals in middle east area were reported from some countries such as Iraq [25], Pakistan [26], Saudi Arabia [27], and Turkey [28]. Likewise, some studies published on the prevalence of fascioliasis from several regions of Iran [29-32].

Traditional and non-standard animal husbandry and the presence of large snail population are suggested to be important in the distribution of the disease 
in different parts of Iran. After the large outbreaks in $90 \mathrm{~s}$ and 2000s, fascioliasis has been considered as one of the serious health concerns of the area and exerted heavy impact on the economy and social welfare of the people in Iran. Obtaining epidemiological data seem essential before managing any control programs. Information resulting from slaughterhouses records has been known as useful sources of data for the study of epidemiological aspects of certain diseases $[33,34]$. Therefore, this study was conducted to evaluate the prevalence and possible trends of fascioliasis in common meat production animals slaughtered in Jahrom district (south of Iran) based on abattoir data over a period of 5 years.

\section{Materials and Methods}

\section{Ethical approval}

The experiment on animals including all procedures of this study was approved by the local Ethical Committee in Jahrom University of Medical Sciences

\section{Study area}

The present study is a retro-perspective study conducted at the main slaughterhouse of Jahrom region which is located in south of Iran. Geographically, Jahrom district is located between $28.19^{\circ}$ and $29.10^{\circ}$ latitude north and $52.45^{\circ}$ and $54.4^{\circ}$ longitude east. Jahrom is situated in a zone with $1050 \mathrm{~m}$ height from sea level, with the vast citrus gardens, where the mean monthly temperature is $21^{\circ} \mathrm{C}$. However, during the warmest period (June-August) the mean average temperature goes up to $40^{\circ} \mathrm{C}$, during the cooler months (December-February) the temperature drops to below $0^{\circ} \mathrm{C}$. The region has a relatively poor rainfall patterns and receives around $250 \mathrm{~mm}$ of rainfall annually.

\section{Animals}

The study was a retrospective abattoir survey, undertaken for 5 years from March 2011 to April 2015 which included cattle, goat, and sheep slaughtered at Jahrom main abattoir. Animals were brought there from different parts of Jahrom region. These places were in different geographical locations but more or less with the same climatic conditions, and rose with the similar animal husbandry method.

All daily records for cattle, sheep, and goats slaughtered in the main abattoir of Jahrom district were extracted from the archived documents of the recent 5 years and used as data for further evaluation. The information was collected on a monthly basis to indicate any seasonal trends.

\section{Statistical analysis}

For clarifying the factors associated with the rate of fasciolosis, the collected data were statistically analyzed using SPSS software. The $\mathrm{p}<0.05$ considered statistically significant.

\section{Results}

In total, 190,277 animals (cattle 12,079, sheep 44,191 and goats 134,007) were slaughtered in Jahrom District during 2011 to 2015 . Overall, 3.44\% of all animals' liver was condemned because of infection with Fasciola spp.

Among the animals, fasciolosis was detected in $11.15 \%$ of cattle, $5.22 \%$ of sheep, and $2.15 \%$ of goat. In this regard, analyzing the data related to the rate of infection between different animal showed that there was highly significant difference in Fasciola spp. infection within animals $(\mathrm{p}<0.001)$, in which infection of cattle was considerably higher than sheep and goats (Table-1).

The seasonal pattern for liver condemnation during the 5 years is illustrated in Figure-1. Briefly, the maximum and minimum rate of fasciolosis was seen in winter $(4.02 \%)$ and summer $(2.86 \%)$, respectively (Table-1). Comparing the result of infection rates showed that there was statistically significant difference with respect to season $(\mathrm{p}<0.005)$.

As it is shown in Figure-2, annual trend of infection showed a gradual reduction from 5.5\% infection rate in 2011 to $2.11 \%$ in 2015 , which was statistically significant.

In addition, regarding the different animals, a gradual decline was seen in the infection rate of Fasciola spp. in goat and sheep. In cattle, the rate of infection raised at the first years, followed by a remarkable diminution in the next years (Figure-3).

\section{Discussion}

The prevalence rate of liver trematodes in ruminants varies markedly worldwide. Fasciola spp. are frequently found in herbivores in different parts of

Table-1: Prevalence and seasonal distribution of Fasciola spp. infection in different animals slaughtered in Jahrom, South of Iran, 2011-2015.

\begin{tabular}{|c|c|c|c|c|}
\hline \multirow[t]{2}{*}{ Animals } & \multirow[t]{2}{*}{ Number of examined } & \multirow[t]{2}{*}{ Number of infected (\%) } & \multicolumn{2}{|c|}{ 95\% Confidence interval } \\
\hline & & & Lower bound & Upper bound \\
\hline Sheep & 44,191 & $2310(5.23)$ & 5.2103 & 5.2443 \\
\hline Goat & 134,007 & $2887(2.15)$ & 2.1490 & 2.1597 \\
\hline Cattle & 12,079 & $1347(11.15)$ & 11.0598 & 11.2433 \\
\hline \multicolumn{5}{|l|}{ Seasons } \\
\hline Spring & 44,833 & $1378(3.07)$ & 3.0442 & 3.1030 \\
\hline Summer & 47,967 & $1371(2.86)$ & 2.8382 & 2.8866 \\
\hline Autumn & 45,835 & $1719(3.75)$ & 3.7203 & 3.7761 \\
\hline Winter & 51,642 & $2076(4.02)$ & 3.9938 & 4.0423 \\
\hline Total & 190,277 & $6544(3.44)$ & 3.4258 & 3.4526 \\
\hline
\end{tabular}




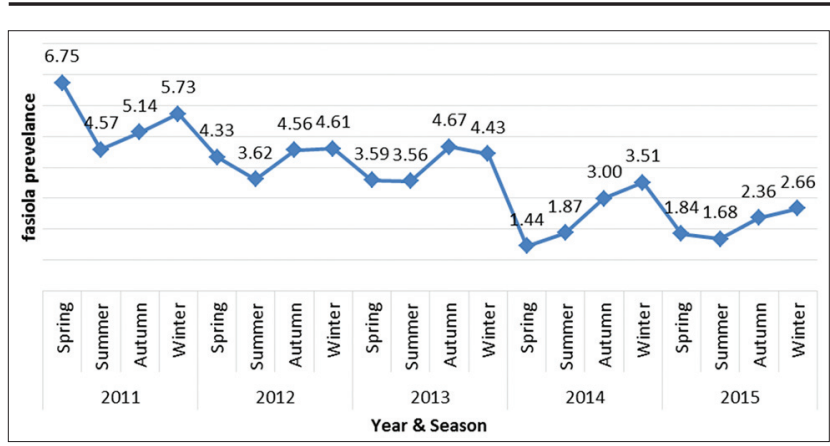

Figure-1: Seasonal trend of Fasciola spp. infection in animals slaughtered in Jahrom, South of Iran, in each years of 2011-2015.

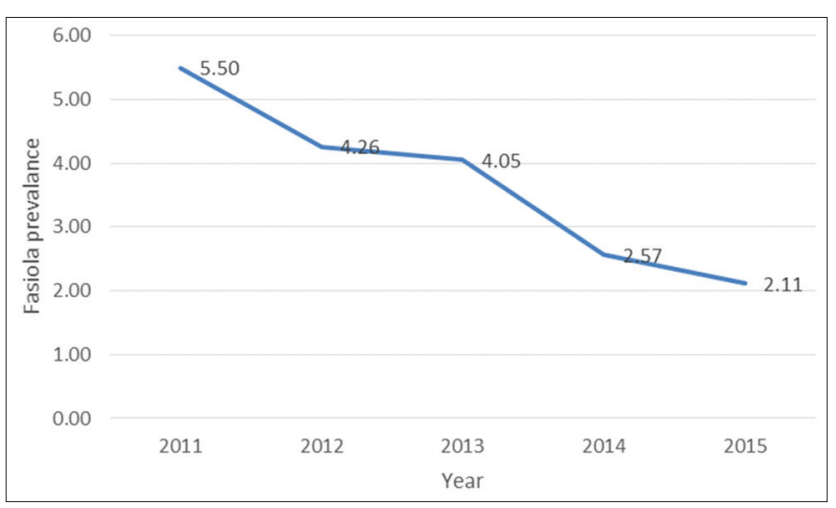

Figure-2: Annual trend of Fasciola spp. infection in animals slaughtered in Jahrom, South of Iran, 2011-2015.

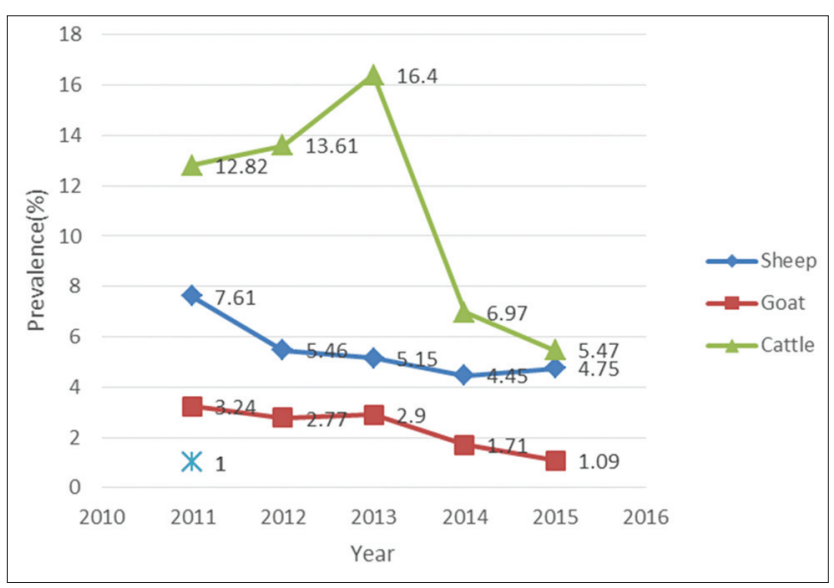

Figure-3: Annual trend of Fasciola spp. infection in different animals slaughtered in Jahrom, south of Iran, 2011-2015.

Iran $[13,35]$. Several large epidemics of fasciolosis, including thousands of human infection, were reported from north of Iran [24,31]. In addition, another epidemic was observed in Kermanshah (west of Iran) in 2000 [36].

In this survey, $3.44 \%$ of all slaughtered animals during 2011-2015 were infected with Fasciola spp. In other words, the mean prevalence of Fasciola spp. was $11.15 \%, 5.22 \%$ and $2.15 \%$ for cattle, sheep, and goat, respectively.

The previous studies carried out in various regions of Iran depicted different prevalence rates of Fasciola spp. in livestock. A study conducted in Lorestan (southwest of Iran) indicated prevalence rate of fasciolosis among sheep and goat as $7.1 \%$ and $3.9 \%$, respectively [37]. Similarly, Movassagh showed that $8.57 \%$ of sheep livers were polluted by Fasciola hepatica in the Northwest of Iran [38]. Daryani observed that $25.9 \%$ of cattle, $5.3 \%$ of sheep, and $4.9 \%$ of goat were infected by Fasciola spp.; which is compatible with our findings in Jahrom about sheep and goat, whereas the result of cattle was higher than our results [29]. Moreover, an abattoir survey in Ardabil showed that among liver flukes infections, fasciolosis was detected in $25.6 \%$ of cattle and $21.6 \%$ of sheep [39].

In the vicinity of Iran, there were reports of variable fasciolosis rate in ruminants. In Pakistan (east of Iran), a considerably high prevalence rate of F. hepatica in cattle $(85.1 \%)$, sheep $(51.3 \%)$ and goats (14.8\%) was reported [40]. In contrast, a very low prevalence was observed in Iraq, where an abattoir data indicated that fasciolosis rate in cattle, sheep and goat was $0.13 \%, 0.72 \%$, and $3.30 \%$, respectively [41]. Furthermore, fasciolosis has been reported in $3.99 \%$ of sheep and $0.48 \%$ of cattle in Turkey [28].

The differences observed could be explained through the existence of various factors such as husbandry practices and climatic variation. Rainfall and temperature were among those climate items considered as effective factors in the distribution of fasciolosis among herbivores [42]. A probable reason could be the fact that rainfall and temperature had a significant impact on the survival of both intermediate host and the larval stages (miracidium and cercariae) of the parasite [43].

In this regard analyzing, the data related to the prevalence of fasciolosis in different season indicated that there was a distinct correlation between season and fasciolosis among animals. As indicated in Table-1, liver condemnations due to fasciolosis were more prevalent in animals slaughtered during winter, whereas the lowest rate of infection was seen in summer. The higher rate of fasciolosis during winter might be correlated with the above mentioned meteorological factors, in which higher rainfall in winter probably caused the higher population of snails and consequently increasing the infection in animals. Moreover, it could be hypothesized that the reduction of infection in animals accompanied by very hot and dry environmental condition at summer [30]. A distinct seasonal pattern for fasciolosis among herbivores was reported in most of epidemiological surveys [37,44-48]. All studies had a common point that, the rainier the season, the more fasciolosis infection indicated.

These are other factors contributing to the epidemiological aspects of fasciolosis. For example, certain kinds of soil affect the distribution of intermediate host in environment [49,50]. Regardingly, all criteria related to soil, including minerals, porosity, $\mathrm{pH}$ and other physical and chemical characteristics of the soil are deemed to be important in this subject $[51,52]$. This indicates the complexity of the various aspects of 
fasciolosis cycle, which suggests for further work to properly determine all the possible factors associated with the fasciolosis prevalence.

Our findings were also in agreement with that of those who find a higher rate of infection in cattle compared to sheep and goat $[3,29]$. Similar results were also reported in Kenya where a considerable rate of fasciolosis was seen in cattle $(52.6 \%)$ compared to sheep (18.3\%) and goat (16.9\%) [53]. In a 10 years abattoir investigation in Khuzestan province, higher fasciolosis prevalence was observed among cattle $(5.54 \%)$, more than sheep $(0.93 \%)$, and goat $(2.79 \%)$ [30].

On the other hands, Talari, in a 3-year abattoir investigation, reported a lower prevalence of fasciolosis in cattle (2.4\%) than sheep $(6.9 \%)$ and goat $(4.1 \%)$ which was clearly contrary to our results [44].

Moreover, the previous studies indicated that fasciolosis rate in sheep was significantly higher than goat [3], which was compatible with the results of our study.

An abattoir data survey of slaughtered animals of Mazandaran (north of Iran) revealed that $5.7 \%$ of sheep and $1.6 \%$ of goats were infected with Fasciola spp. [31].

The epidemiologic notion of this finding might be attributed to the grazing style of animals on grassland. Cattle usually tend to pasture near the springs and streams, where the snails are more frequently present. In contrast, goats usually have the lowest rate of infection compared to sheep and cattle. The grazing style of goat is different from that of sheep, in a way that they naturally tend to eat leaves and heaths in elevated areas, contrary to sheep that often graze on the land; this way of pasturing may reduce the contact with infective metacercariae and more probably reduces the risk of infection in goat.

It is worth to mention that our findings showed a gradual reduction of fasciolosis from the beginning of 2011 to the end of 2015. In cattle, the story was a bit different: The graph showed a raising trend at the first years, following by a steep slope of diminution at the end of the period. The animal husbandry method could explain the variation observed in the distribution of fasciolosis in different regions. After several epidemics in Iran, the awareness among farmers to standardize the method of husbandry was remarkable. Moreover, effective using of available treatments (triclabendazole or albendazole) has been widely developed in recent years that brought about reduction in all types of veterinary parasites including fasciolosis [30]. Cattle husbandry has dramatically changed during the years. Today, cattle usually are kept in modern farms with less contact with environment, and this has led lower infection in animals compared to the past.

\section{Conclusion}

Regarding the foregone discussion, we observed a relatively low prevalence and also a significant reduction of fasciolosis among sheep, cattle, and goats during the recent 5 years. A wide spectrum of factors has been suggested that affects the distribution of fasciolosis in animals and human; thus, further studies should be done to clarify the whole aspects of fasciolosis. Abattoir surveys could be helpful as it provided useful preliminary information for further monitoring. Logically, although the slaughterhouse data might not be equal to the real population of animals, it could be considered as a marker of real infection in population. In addition, it seems useful for managing and evaluating the control and prevention programs.

\section{Authors' Contributions}

BA and MSK have designed the concept and supervised the plan of work and also have prepared the manuscript. HD, MEJ, and MSK have contributed in data collection, administrative, technical, and material support. KS and BA have analyzed and interpreted the data.

\section{Acknowledgments}

The authors would like to thank the personnel of Jahrom main slaughterhouse for their kind assistance. This study was financially supported by Zoonosis Research Center of Jahrom University of Medical Sciences, Iran (IR.JUMS.REC.1390.088).

\section{Competing Interests}

The authors declare that they have no competing interests.

\section{References}

1. Ahmadi, N.A. and Meshkehkar, M. (2010) Prevalence and long term trend of liver fluke infections in sheep, goats and cattle slaughtered in Khuzestan, Southwestern Iran. J. Paramed. Sci., 1(2): 26-31.

2. Ali, T.S., Zarichehr, V., Reza, T.M., Amroallah, B., Hossin, T., Amir, M. and Hassan, E. (2011) Prevalence of liver flukes infections in slaughtered animals in Kashan, Isfahan province, Central Iran. IIOAB J., 2(5): 14-18.

3. Ansari-Lari, M. and Moazzeni, M. (2006) A retrospective survey of liver fluke disease in livestock based on abattoir data in Shiraz, South of Iran. Prev. Vet. Med., 73(1): 93-96.

4. Ashrafi, K., Massoud, J., Holakouei, K., Mahmoodi, M., Joafshani, M.A., Valero, M.A. and Bargues, M.D. (2004) Evidence suggesting that Fasciola gigantica might be the most prevalent causal agent of fascioliasis in Northern Iran. Iran. J. Public. Health, 33(4): 31-37.

5. Ashrafi, K., Valero, M.A., Forghan-Parast, K., Rezaeian, M., Shahtaheri, SJ., Hadiani, M.R. and Mas-Coma, S. (2006) Potential transmission of human fascioliasis through traditional local foods in Northern Iran. Iran. J. Public Health, 35(2): 57-63.

6. Ashrafi, K. (2015) The status of human and animal fascioliasis in Iran: A narrative review article. Iran. J. Parasitol., 10(3): 306 .

7. Ashrafi, K., Valero, M.A., Peixoto, R.V., Artigas, P., Panova, M. and Mas-Coma, S. (2015) Distribution of Fasciola hepatica and F. gigantica in the endemic area of Guilan, Iran: Relationships between zonal overlap and phenotypic traits. Infect. Genet. Evol., 31: 95-109.

8. Assmar, M., Milaninia, A., Amikhani, A., Yadegari, D., Forghanparast, K., Nahravanian, H. and Valadkhani, Z.A.J. (1991) Seroepidemiological investigation of fascioliasis in 
northern Iran. Med. J. Islam. Repub. Iran., 5(1): 23-27.

9. Byrne, A.W., McBride, S., Lahuerta-Marin, A., Guelbenzu, M., McNair, J., Skuce, R.A. and McDowell, S.W.J. (2016) Liver fluke (Fasciola hepatica) infection in cattle in Northern Ireland: A large-scale epidemiological investigation utilising surveillance data. Parasitol. Vectors, 9(1): 1.

10. Charlier, J., Bennema, S.C., Caron, Y., Counotte, M., Ducheyne, E., Hendrickx, G. and Vercruysse, J. (2011) Towards assessing fine-scale indicators for the spatial transmission risk of Fasciola hepatica in cattle. Geospat. Health, 5(2): 239-245.

11. Daryani, A., Alaei, R., Arab, R., Sharif, M., Dehghan, M.H. and Ziaei, H. (2006) Prevalence of liver fluke infections in slaughtered animals in Ardabil province, Northwestern Iran. J. Anim. Vet. Adv., 5(5): 408-411.

12. Ejeh, E.F., Paul, B.T., Lawan, F.A., Lawal, J.R., Ejeh, S.A. and Hambali, I.U. (2015) Seasonal prevalence of bovine fasciolosis and its direct economic losses (del) due to liver condemnation at Makurdi abattoirs North Central Nigeria. Sokoto. J. Vet. Sci., 13(2): 42-48.

13. Ezatpour, B., Hasanvand, A., Azami, M., Anbari, K. and Ahmadpour, F. (2015) Prevalence of liver fluke infections in slaughtered animals in Lorestan, Iran. J. Parasit. Dis., 39(4): 725-729.

14. Farid, H. (1971) Human infection with Fasciola hepática and Dicrocoelium dendriticum in Isfahan area, Central Iran. J. Parasitol., 57(1): 160.

15. Fürst, T., Keiser, J. and Utzinger, J. (2012) Global burden of human food-borne trematodiasis: A systematic review and meta-analysis. Lancet. Infect. Dis., 12(3): 210-221.

16. Gargili, A., Tüzer, E., Gülenber, A., Toparlak, M., Efil, I., Keleş, V. and Ulutaş, M. (1999) Prevalence of liver fluke infections in slaughtered animals in Trakya (Thrace), Turkey. Turk. J. Vet. Anim. Sci., 23(2): 115-116.

17. Ghazaei, C. (2007) An abattoir survey of hydatid and liver fluke disease in sheep and cattle in Ardabil abattoir, Ardabil state, Iran. J. Anim. Vet. Adv., 6(5): 595-596.

18. Ghazani, M.H.M., Valilou, M.R., Ahmadzadeh, A.R., Karami, A.R. and Zirak, K. (2008) The prevalence of sheep liver trematodes in the Northwest region of Iran. Turk. J. Vet. Anim. Sci., 32(4): 305-307.

19. Haleem, S., Shadab F, Niaz S., Rehman, H.U., Sajad, S., Qureshi, N.A. and Kabir, M. (2016) Prevalence of fascioliasis in cows and sheep in district Mardan (KPK), Pakistan. J. Entomol. Zool. Stud., 4(3): 330-334.

20. Hassan, N.O. (2015) Prevalence of some infections in liver and lung of slaughtered ruminants in Koya abattoir, Erbil, Iraq. Tikrit J. Pure Sci., 20(2): 1-6.

21. Hatami, H., Asmar, M., Massoud, J., Aryanifar, S., Mansori, F., Fatemi, S. and Namdaritabar, H. (2000) Report of the first outbreak of human fasciolosis in Kermanshah province. Moddares J., 3: 79-87.

22. Hosseini, G., Sarkari, B., Moshfe, A., Motazedian, M.H. and Khabisi, S.A. (2015) Epidemiology of human fascioliasis and intestinal helminthes in rural areas of boyer-Ahmad township, Southwest Iran; A population based study. Iran. J. Public Health, 44(11): 1520.

23. Ibrahem, M.M. and Craig, P.S. (1998) Prevalence of cystic echinococcosis in camels (Camelus dromedarius) in Libya. J. Helminthol, 72(1): 27-31.

24. Khanjari, A., Partovi, R., Abbaszadeh, S., Nemati, G., Bahonar, A., Misaghi, A. and Motaghifar, A. (2012) A retrospective survey of fasciolosis and dicrocoeliosis in slaughtered animals in Meisam abattoir, Tehran, Iran (2005-2008). Vet. Res. Forum., 1(3): 174-178.

25. Kithuka, J.M., Maingi, N., Njeruh, F.M. and Ombui, J.N. (2002) The prevalence and economic importance of bovine fasciolosis in Kenya-an analysis for abattoir data. Onderstepoort J. Vet. Res., 69(4): 255

26. Mahdi, N.K. and Al-Baldawi, F.A. (1987) Hepatic fascioliasis in the abattoirs of Basra. Ann. Trop. Med. Parasitol.,
81(4): 377-379.

27. Mas-Coma, M.S., Esteban, J.G. and Bargues, M.D. (1999) Epidemiology of human fascioliasis: A review and proposed new classification. Bull. World Health Organ., 77(4): 340-346.

28. Mas-Coma, S., Bargues, M.D. and Esteban, J.G. (1999) Human fasciolosis. Fasciolosis. In: Dalton, J.P., editor. CABI Publishing, CAB International, Wallingford, UK. p411-434.

29. Mas-Coma, S., Bargues, M.D. and Valero, M.A. (2005) Fascioliasis and other plant-borne trematode zoonoses. Int. J. Parasitol., 35(11): 1255-1278.

30. Massoud, J. (1990) Fascioliasis outbreak of man and drug test (triclabendazole) in Caspian Sea littoral, Northern part of Iran. Bull. de la Soc. Fr. De Parasitol., 8: 438-438.

31. Massoud, J. (1993a) Present Status of Fasciolosis in Iran: Document SCH/SG/93/WP. World Health Organization, Geneva.

32. Massoud, J. (1993b) Present status of human fascioliasis in Iran. Food-borne Trematods. World Health Organization, Manila.

33. Moghaddam, A.S., Massoud, J., Mahmoodi, M., Mahvi, A.H., Periago, M.V., Artigas, P. and Mas-Coma, S. (2004) Human and animal fascioliasis in Mazandaran province, Northern Iran. Parasitol. Res., 94(1): 61-69.

34. Novobilský, A., Engström, A., Sollenberg, S., Gustafsson, K., Morrison, D.A. and Höglund, J. (2014) Transmission patterns of Fasciola hepatica to ruminants in Sweden. Vet. Parasitol., 203(3): 276-286.

35. Novobilský, A., Kašný, M., Beran, L., Rondelaud, D. and Höglund, J. (2013) Lymnaea palustris and Lymnaea fuscus are potential but uncommon intermediate hosts of Fasciola hepatica in Sweden. Parasit. Vectors, 6(1): 251.

36. Novobilský, A., Novák, J., Björkman, C. and Höglund, J. (2015) Impact of meteorological and environmental factors on the spatial distribution of Fasciola hepatica in beef cattle herds in Sweden. BMC Vet. Res., 11(1): 1.

37. Nyindo, M. and Abdul-Hamid, L. (2015) Fascioliasis: An ongoing zoonotic trematode infection. BioMed Res. Int., 2015: 1-8.

38. Okajima, J., Shibata, K., Takahashi, E., Nagafuchi, T., Okajima, K. and Nonaka, N. (2016) Current status and its epidemiological consideration of Fasciola and Eurytrema infections in beef cattle of Japan. J. Vet. Med. Sci., 78(5): 785-790.

39. Ollerenshaw, C.B. and Smith, L.P. (1969) Meteorological factors and forecasts of helminthic disease. Adv. Parasit., 7: 283-323.

40. World Health Organization. (1995) Control of foodborne trematode infections: Report of a WHO study group. World Health Organ. Tech. Rep. Ser., 849: 1-157.

41. Otranto, D. and Traversa, D. (2002) A review of dicrocoeliosis of ruminants including recent advances in the diagnosis and treatment. Vet. Parasitol., 107(4): 317-335.

42. Pantelouris, E.M. (2013) The Common Liver Fluke: Fasciola bepatica L. Elsevier, Amsterdam.

43. Rokni, M.B. (2008) The present status of human helminthic diseases in Iran. Ann. Trop. Med. Parasitol., 102(4): 283-295.

44. Saberinasab, M., Mohebali, M., Molawi, G., Kia, E.B., Aryaeipour, M. and Rokni, M.B. (2014) Seroprevalence of human fascioliasis using indirect ELISA in Isfahan district, central Iran in 2013. Iran. J. Parasitol., 9(4): 461-465.

45. Sayadi, M., Mohammad-Pourfard, I., Yahyaei, M. and Esmaeili, R. (2015) The prevalence of fascioliasis in slaughtered animals of the industrial slaughterhouse of arak, Iran (2007-2010). Iran. J. Health Sci., 3(4): 59-64.

46. Schweizer, G., Plebani, G.F. and Braun, U. (2003) Prevalence of Fasciola hepatica and Dicrocoelium dendriticum in the cow: Inspection in an east Switzerland abattoir. Schweiz. Arch. Tierheilkd., 145(4): 177-179.

47. Shafiei, R., Sarkari, B., Sadjjadi, S.M., Mowlavi, G.R. and 
Moshfe, A. (2014) Molecular and morphological characterization of Fasciola spp. Isolated from different host species in a newly emerging focus of human fascioliasis in Iran. Vet. Med. Int., 2014: 1-14.

48. Shalaby, I., Gherbawy, Y. and Banaja, A. (2013) Molecular characterization of Fasciola species isolated from imported sheep in Ta'if region (Saudi Arabia). Trop. Biomed., 30(1): 15-26.

49. Sharma, R.L. and Raina, O.K. (1989) Studies on the prevalence and laboratory transmission of fascioliasis in animals in the Kashmir valley. Br. Vet. J., 145(1): 57-61.
50. Toledo, R., Esteban, J.G. and Fried, B. (2012) Current status of food-borne trematode infections. Eur. J. Clin. Microbiol. Infect. Dis., 31(8): 1705-1718.

51. Torgerson, P. and Claxton, J. (1999) Epidemiology and Control: Fasciolosis. CAB International Publishing, UK.

52. Yadegari, D., Forghanparast, K. and Assmar, M. (1990) Investigation of an epidemic of fascioliasis in north Iran. Bull. Soc. Fr. Parasitol., 8 Suppl 2: 868.

53. Yusuf, M., Ibrahim, N., Deneke, Y. and Tafese, W. (2016) Prevalence of bovine fasciolosis in municipal abattoir of Haramaya, Ethiopia. Food Sci. Qual. Manageme, 48: 38-43.

\section{$* * * * * * * *$}

